\title{
The influence of pre-compounding techniques and surface modification of nano-silica on the properties of thermoplastic natural rubber
}

\author{
M. Jarnthong ${ }^{1,2}$, Z. Peng ${ }^{1}$, N. Lopattananon ${ }^{2}$, C. Nakason ${ }^{3 *}$ \\ ${ }^{1}$ Guangdong Provincial Key Laboratory of Natural Rubber Processing, Agricultural Products Processing Research \\ Institute of Chinese Academy of Tropical Agricultural Sciences, Zhanjiang 524001 Guangdong, China \\ ${ }^{2}$ Department of Rubber Technology and Polymer Science, Faculty of Science and Technology, Prince of Songkla \\ University, 94000 Pattani, Thailand \\ ${ }^{3}$ Faculty of Science and Industrial Technology, Prince of Songkla University, 84000 Surat Thani, Thailand
}

Received 20 May 2021; accepted in revised form 17 July 2021

\begin{abstract}
Thermoplastic natural rubber (TPNR) nanocomposites based on epoxidized natural rubber (ENR) and polypropylene (PP) blends filled with $2.5 \mathrm{wt} \%$ nano-silica $\left(\mathrm{SiO}_{2}\right)$ were prepared using a two-step compounding process to improve the dispersion of $\mathrm{SiO}_{2}$ in TPNR. The effects of the compounding techniques, i.e., solid pre-compounding and latex pre-compounding processes of $\mathrm{SiO}_{2}$ and $\mathrm{ENR}$, and surface modification of $\mathrm{SiO}_{2}$ on the morphological, mechanical, and thermal properties together with the crystallization behavior of PP phase in ENR/PP blends were demonstrated. Scanning electron microscope (SEM) results showed that latex pre-compounding of $\mathrm{SiO}_{2}$ and $\mathrm{ENR}$ gave finer dispersion and distribution of $\mathrm{SiO}_{2}$ particles in the TPNR matrix as compared with the solid pre-compounding technique. Also, the superior mechanical properties and thermal stability of the blends were achieved by using the latex pre-compounding technique. Moreover, surface modification of $\mathrm{SiO}_{2}$ by organosilane was found to enhance crystallization rate and the degree of crystallinity of PP phase in the TPNR, leading to an improvement in the strength and mechanical properties of the ENR/PP blends. These results agree well with the morphological properties that presented a good dispersion and distribution of silane-modified $\mathrm{SiO}_{2}$ particles in the TPNR matrix.
\end{abstract}

Keywords: nanocomposites, nano-silica, thermoplastic natural rubber, latex pre-compounding, solid pre-compounding

\section{Introduction}

Development of thermoplastic elastomers (TPEs) by mixing natural rubber (NR) biomaterial with crystalline thermoplastics provides a new material called thermoplastic natural rubber (TPNR). This type of material has drawn the interest of the scientific community because it is an eco-friendly renewable resource material, which can be recycled, reused, and reprocessed while retaining the key characteristics of both thermoplastics and natural rubber, namely high mechanical strength and elasticity, respectively. Compatibility between NR and thermoplastics is one of the key factors affecting the properties of the TPNR. A high degree of compatibility results in high mechanical properties of this material $[1,2]$. Beyond using NR in its normal state, chemically modified natural rubber, i.e., epoxidized natural rubber (ENR) [3-5], maleated natural rubber (MNR) [6, 7], and natural rubber-graft-poly(methyl methacrylate) (NR-gPMMA) $[1,8,9]$, have also been frequently utilized to prepare TPNRs. The main aim of the chemical modification was to improve the thermal resistance of the rubber phase and the compatibility between natural rubber and thermoplastics. Furthermore, 
some properties of TPNRs, including dimension stability, thermal resistance, gas barrier, mechanical, electromagnetic, and microwave absorbing properties, can be augmented through the addition of certain particulate particles, including nanoclay $[10,11]$, carbon nanotubes $[12,13]$, alumina nanoparticles [14], nickel zinc ferrite nanoparticles $[15,16]$ and nano-silica $[3,17]$. With proper dispersion and distribution of these fillers in the rubber and thermoplastic phase, high interfacial areas between the filler particles and polymer surfaces can be achieved. This leads to the enhancement of the most important strength and electrical properties of composite materials. Unfortunately, the homogeneous dispersion of nanoparticles in the polymer matrix is rather difficult to achieve due to higher filler-filler than filler-polymer interactions during processing, causing the formation of aggregates and large agglomerates in the polymer matrix. These agglomerates may act as defects and weak spots which diminish the final properties of the nanocomposites. Several attempts and feasibility studies have been made to establish a suitable method to overcome this problem. These include surface modification of nanoparticles [18-20], exploitation of the silane coupling agent $[21,22]$, and an ultrasonication-assisted mixing method [23]. Incorporation of nanofiller into rubber latex or latex compounding is one of the eco-friendly strategies that has been frequently used to obtain a finer dispersion of nanoparticles in the rubber matrix without using solvent [20,24-31]. This technique comes with various advantages, including a simple preparation process and the fact that it is non-toxic, low cost, and energy-efficient since the procedure is done by simple mixing of nanoparticles in a water suspension with rubber latex at very low viscosity [28]. It has been reported that the clay layers were successfully exfoliated and homogeneously dispersed in the polymer matrix by using the latex compounding method $[28,29]$. In addition, NR/silica nanocomposites were prepared using the latex compounding method. It was found that the synergistic effect of ball milling and modification of nano-silica could simultaneously increase the dispersibility of silica and improve the interaction between silica and NR, which would, in turn, improve the performance of the NR composites [30]. Also, the benefits of the latex mixing process in polymer blend nanocomposites have been reported in the preparation of a natural rubber (NR)/highdensity polyethylene (HDPE) blend filled with graphene oxide (GO) [31]. It was found that the stacked GO platelets were successfully exfoliated in NR by using the latex mixing process prior to meltblending with HDPE, which thereafter provided good compatibilization efficiency in the immiscible NR and HDPE blends.

Nano-silica $\left(\mathrm{SiO}_{2}\right)$ is one of the promising fillers for polymer nanocomposites due to its reactive high specific surface area, which can act as a reinforcing filler and nucleating agent [32-34]. In our previous study, the solid compounding process was used to prepare nano-silica filled ENR/polypropylene (PP) nanocomposites. Beyond this, the mixing sequence of nanosilica into ENR/PP blends was investigated [3]. It was found that the pre-compounding of nano-silica in ENR prior to melt-mixing with PP could provide finer dispersion of nano-silica in the polymer matrix. This led to enhanced mechanical properties, damping, and thermal stability of the blends. To further enhance the potential properties of ENR/PP nanocomposites, in this work, the latex pre-compounding technique was used to prepare $\mathrm{ENR}$ mixed $\mathrm{SiO}_{2}$ prior to melt-blending with PP to form ENR/PP TPNR nanocomposites. The influence of pre-compounding techniques and surface modification of nano-silica on morphological and mechanical properties together with crystallization behavior of the ENR/PP TPNR nanocomposites were investigated.

\section{Materials and methods}

\subsection{Materials}

Polypropylene (PP), El-Pro ${ }^{\circledR}$ P700J, manufactured by Thai Polypropylene Co., Ltd. (Rayong, Thailand), was used as a thermoplastic matrix to prepare ENR/ PP TPNR. It has a melt mass-flow rate (MFR) of $12 \mathrm{~g} / 10 \mathrm{~min}\left(230^{\circ} \mathrm{C}\right.$ and a deadweight of $\left.2.16 \mathrm{~kg}\right)$ according to ISO 1133. Epoxidized natural rubber (ENR) latex with an epoxidation level of $35 \mathrm{~mol} \%$ epoxide and dry rubber content (DRC) of $20 \mathrm{wt} \%$ was prepared in-house via in situ performic acid epoxidation, as described elsewhere [35, 36]. In brief, the in situ epoxidation was carried out by mixing NR latex $(1.00 \mathrm{~mol})$ with performic acid $(\mathrm{PA})$ with a molar ratio of $\mathrm{NR}: \mathrm{PA}=0.35: 0.5$ at $50{ }^{\circ} \mathrm{C}$ for about $12 \mathrm{~h}$. The obtained ENR latex was then coagulated using ethanol, washed, sheeted out, and dried in a vacuum oven at $40^{\circ} \mathrm{C}$ for $72 \mathrm{~h}$. The dried ENR was then used to prepare the ENR/PP blends both with and without nano-silica. The nano-silica $\left(\mathrm{SiO}_{2}\right)$ used was AEROSIL $^{\circledR} 380$, manufactured by Evonik Degussa 


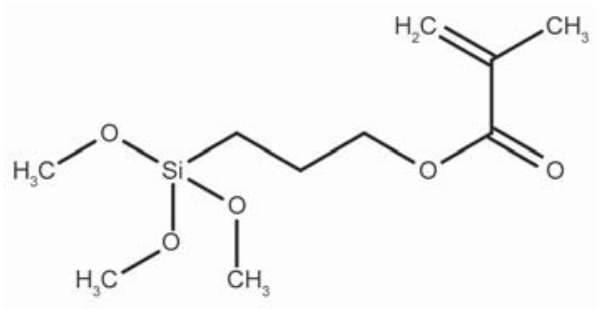

Figure 1. Chemical structure of 3-methacryloxypropyl trimethoxysilane (MPTS).

(Rheinfelden, Germany) with an average particle size of $7 \mathrm{~nm}$. 3-methacryloxypropyl trimethoxysilane (Dynasylan ${ }^{\circledR}$ MEMO or MPTS) was manufactured by Evonik Degussa (Rheinfelden, Germany), with its molecular structure shown in Figure 1. Formic acid and hydrogen peroxide were manufactured by Univar Canada Ltd., Van Horne Way Richmond, Canada.

\subsection{Surface modification of silica nanoparticles}

The MPTS-modified $\mathrm{SiO}_{2}\left(\mathrm{MPTS}-\mathrm{SiO}_{2}\right)$ nanoparticles were prepared using a previously reported procedure [20]. Briefly, MPTS was first hydrolyzed in a mixture of distilled water/ethanol $=5 / 95 \mathrm{wt} \%$ at $\mathrm{pH} 5-6$, stirred continuously for $2 \mathrm{~h}$. The hydrolyzed silane solution was then slowly added into the $\mathrm{SiO}_{2}$ suspension (in $95 \mathrm{wt} \%$ ethanol) with a weight ratio of silane: $\mathrm{SiO}_{2}=1: 10$. The mixture was then continuously stirred for another $2 \mathrm{~h}$ and separated by centrifugation. It was then washed multiple times with ethanol and followed by distilled water in order to remove chemical residues. The MPTS-SiO 2 product was eventually freeze-dried for $48 \mathrm{~h}$ and was then dried in a vacuum oven at $110^{\circ} \mathrm{C}$ for $24 \mathrm{~h}$ and stored in a desiccator before use. The grafting of MPTS on nano-silica surface confirmed by Fourier transform infrared (FTIR) analysis has been reported in our previous study [3]. It was found an additional peak of $\mathrm{C}=\mathrm{O}$ stretching vibration in the MPTS moiety of MPTS- $\mathrm{SiO}_{2}$ at $1720 \mathrm{~cm}^{-1}$ indicating the successful grafting of MPTS molecules on the $\mathrm{SiO}_{2}$ surface.

\subsection{Preparation of ENR-nanosilica masterbatches}

Two different types of nano-silica $\left(\mathrm{SiO}_{2}\right)$, i.e., unmodified $\mathrm{SiO}_{2}$ and MPTS modified silica (i.e., MPTS- $\mathrm{SiO}_{2}$ ), were used at a fixed loading at $5 \mathrm{wt} \%$ of ENR. The preparation of ENR-nano-silica masterbatches was employed as follows:

Latex pre-compounding technique: $1.0 \mathrm{wt} \%$ of $\mathrm{SiO}_{2}$ or MPTS-SiO ${ }_{2}$ was firstly dispersed in deionized water, with sonicating for about $30 \mathrm{~min}$. Then, $5 \mathrm{wt} \%$ of the silica suspension was added into the ENR latex with $35 \mathrm{~mol} \%$ epoxide and DRC of $20 \mathrm{wt} \%$. The mixture was vigorously stirred at room temperature for $2 \mathrm{~h}$ and then coagulated by adding ethanol. After washing with ethanol several times, the coagulum was then dried in a vacuum oven at $40^{\circ} \mathrm{C}$ for $72 \mathrm{~h}$. Solid pre-compounding technique: $5 \mathrm{wt} \%$ of $\mathrm{SiO}_{2}$ or MPTS-SiO ${ }_{2}$ was firstly mixed with dried ENR in an internal mixer (Charoen Tut, Samutprakarn, Thailand) at $80^{\circ} \mathrm{C}$ for $6 \mathrm{~min}$ with a rotor speed of $60 \mathrm{rpm}$. After that, the masterbatch was removed from the mixer and cooled down to room temperature.

\subsection{Preparation of TPNR nanocomposites}

ENR-SiO ${ }_{2}$ or ENR-MPTS-SiO ${ }_{2}$ masterbatches $(52.5 \mathrm{wt} \%)$ from the solid pre-compounding and latex pre-compounding techniques were mixed with $50 \mathrm{wt} \%$ of $\mathrm{PP}$ at $180^{\circ} \mathrm{C}$ for $6 \mathrm{~min}$ in an internal mixer with a rotor speed of $60 \mathrm{rpm}$ to gain 50/50 ENR/PP TPNR. The TPNR without $\mathrm{SiO}_{2}$ was also prepared with the same mixing procedure as the reference material. After coming out of the mixing chamber, the samples were cooled down to room temperature and grounded to form granules with an average size range from $2 \mathrm{~mm}$ to $4 \mathrm{~mm}$ using a Bosco plastic grinder (Bosco engineering, Samutprakarn, Thailand). The TPNR samples were finally fabricated into dumbbell-shaped test specimens (type 2 dumbbell-shaped specimens according to ISO 37) using a TII-90F thermoplastic injection molding machine (Welltec, Machinery, Hongkong, China), at $180^{\circ} \mathrm{C}$ with a screw

Table 1. Sample codes and composition of TPNR and its nanocomposites.

\begin{tabular}{|c|c|c|c|c|c|}
\hline Sample code & $\begin{array}{l}\text { Compounding } \\
\text { technique }\end{array}$ & Type of nano-silica & $\begin{array}{c}\text { ENR content } \\
{[w t \%]}\end{array}$ & $\begin{array}{c}\text { PP content } \\
{[w t \%]}\end{array}$ & $\begin{array}{c}\text { Nano-silica content } \\
{[w \mathbf{w t} \%]}\end{array}$ \\
\hline TPNR & - & - & 50.0 & 50.0 & - \\
\hline s-TPNR-SiO 2 & solid & unmodified & 50.0 & 50.0 & 2.5 \\
\hline s-TPNR-MPTS-SiO 2 & solid & modified with MPTS & 50.0 & 50.0 & 2.5 \\
\hline 1-TPNR-SiO 2 & latex & unmodified & 50.0 & 50.0 & 2.5 \\
\hline 1-TPNR-MPTS-SiO 2 & latex & modified with MPTS & 50.0 & 50.0 & 2.5 \\
\hline
\end{tabular}


speed of $90 \mathrm{rpm}$ and a mold temperature of $30^{\circ} \mathrm{C}$. Table 1 shows sample codes and the composition of all TPNR samples in this study.

\subsection{Characterizations}

The morphological properties of various TPNR samples were examined using a scanning electron microscope (SEM), Hitachi S-4800 and JSM-5200 SEM (JEOL, Tokyo, Japan) at an accelerating voltage of $10 \mathrm{kV}$. The samples were firstly cryogenically fractured in liquid nitrogen. The fractured surfaces were then dried in a vacuum oven at $40^{\circ} \mathrm{C}$ for $3 \mathrm{~h}$ and then sputter-coated with gold-palladium before examination by SEM. To study the surface morphology, ENR and PP phases in ENR/PP blends, the fractured surface was etched by extraction with chloroform at room temperature for $24 \mathrm{~h}$ to remove ENR phase before being dried and sputter coated.

The tensile properties of the TPNR and its nanocomposites were tested using an H10KS Universal testing machine (Hounsfield Test Equipment, Redhill, UK) fitted with a $500 \mathrm{~N}$ load cell and operated at a constant $500 \mathrm{~mm} / \mathrm{min}$ cross-head speed according to ISO 37.

Differential scanning calorimetry (DSC) was performed by using a DSC7 (Perkin-Elmer, Buckinghamshire, UK). The samples were first incorporated in an aluminum pan and then heated from ambient temperature to $200^{\circ} \mathrm{C}$ at a heating rate of $10^{\circ} \mathrm{C} / \mathrm{min}$ under a nitrogen atmosphere. The test was maintained at this temperature for about $5 \mathrm{~min}$ in order to eliminate the previous thermal history. It was then cooled down to $20^{\circ} \mathrm{C}$. The heating test was again performed by raising the temperature from 20 to $200^{\circ} \mathrm{C}$ with the same heating rate of $10^{\circ} \mathrm{C} / \mathrm{min}$. The degree of crystallinity $\left(X_{\mathrm{c}}\right)$ of the PP phase in the ENR/PP blends was calculated based on the melting enthalpy of the second heating thermogram [37], as laid out in Equation (1):

$$
X_{\mathrm{c}}[\%]=\frac{m_{\mathrm{c}} \Delta H_{\mathrm{m}}}{m_{\mathrm{p}} \Delta H_{0}} \cdot 100
$$

where $\Delta H_{\mathrm{m}}$ is the melting enthalpy measured in the heating experiments, $\Delta H_{0}$ is the theoretical value of enthalpy of $100 \%$ crystalline PP, which was $207.1 \mathrm{~J} / \mathrm{g}$ [32], $m_{\mathrm{c}}$ is the mass of the sample, and $m_{\mathrm{p}}$ is the mass of $\mathrm{PP}$ in the blend sample.

The X-ray diffraction (XRD) analysis of the PP phase in the ENR/PP TPNR and its nanocomposites was carried out by using an X'Pert MPD, Philips X-ray diffractometer (Philips, Almelo, The Netherlands) with a $\mathrm{Cu} \mathrm{K} \alpha$ radiation wavelength of $0.154 \mathrm{~nm}$. Diffraction patterns were operated at $40 \mathrm{kV}$ and collected in reflection-mode geometry from 5 to $35^{\circ} 2 \theta$. Thermogravimetric analysis (TGA) was performed using an STA 6000 (Perkin-Elmer, Norwalk, CT, USA) to determine the degradation temperature $\left(T_{\mathrm{d}}\right)$ of TPNR and its nanocomposites. About $10 \mathrm{mg}$ samples were heated from ambient temperature to $800^{\circ} \mathrm{C}$ with a heating rate of $10^{\circ} \mathrm{C} / \mathrm{min}$ under a nitrogen atmosphere.

\section{Results and discussion \\ 3.1. Dispersion of nano-silica in TPNR nanocomposites}

Unmodified $\mathrm{SiO}_{2}$, MPTS modified $\mathrm{SiO}_{2}$, and fracture surfaces of TPNR nanocomposites prepared by solid and latex pre-compounding techniques reinforced by unmodified $\mathrm{SiO}_{2}$ and MPTS modified $\mathrm{SiO}_{2}$ were examined by SEM, and the results are shown in Figure 2. From our previous work [3], pre-compounding of nano-silica in ENR phase prior to mix with PP provided the morphology of nano-silica dispersed mainly in the ENR phase of the ENR/PP blend. In this study, the encapsulated structure of nano-silica in the ENR phase was assumed. It can be seen that a large agglomeration of unmodified $\mathrm{SiO}_{2}$ particles was formed in the ENR phase for the unmodified $\mathrm{SiO}_{2}$ filled TPNR nanocomposite prepared using solid precompounding (Figure 2c). However, in Figure 2d, the unmodified $\mathrm{SiO}_{2}$ pre-compounded in ENR using the latex pre-compounding technique prior to preparation of the TPNR nanocomposites showed finer dispersion of nanoparticles in the ENR phase. This could be attributed to the much lower viscosity of the ENR latex during the incorporation of nano-silica particles while forming the ENR masterbatch. Also, the distances between the ENR particles in water media allow the $\mathrm{SiO}_{2}$ particles to get closer to the rubber molecules than when prepared by the solid mixing technique (i.e., in Figure 2c). This resulted in finer dispersion and distribution of $\mathrm{SiO}_{2}$ particles in the ENR matrix with the latex mixing method. Therefore, the $\mathrm{SiO}_{2}$ in the ENR phase exhibited a more uniform dispersion in ENR than that of the solid pre-compounding method.

In Figures $2 \mathrm{e}$ and $2 \mathrm{f}$, it is clear that the size of nanoparticles in the ENR matrix was reduced in the TPNR with MPTS modified $\mathrm{SiO}_{2}$ surfaces as compared with the unmodified $\mathrm{SiO}_{2}$ for both solid and latex 


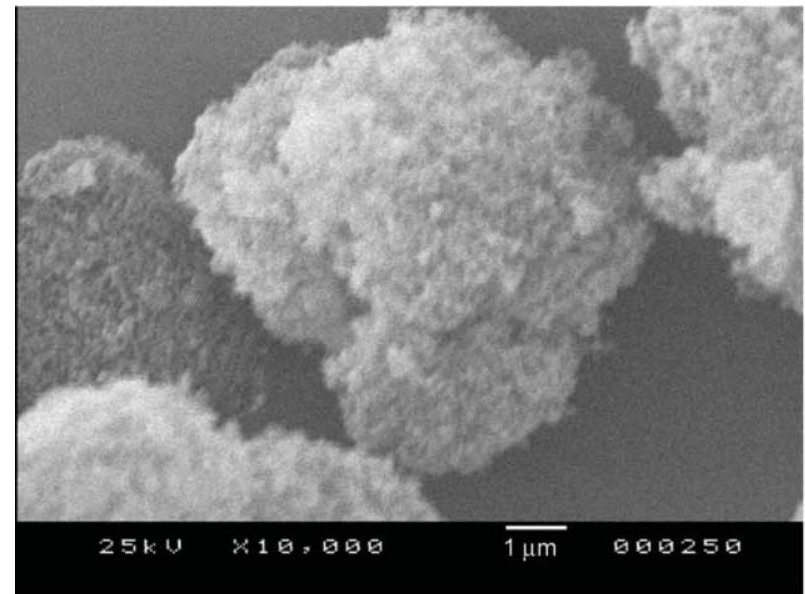

a)

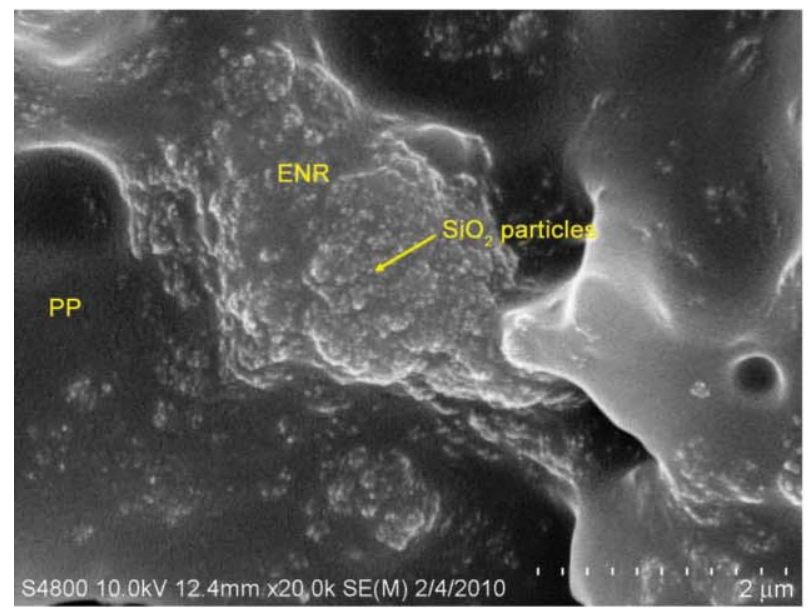

c)

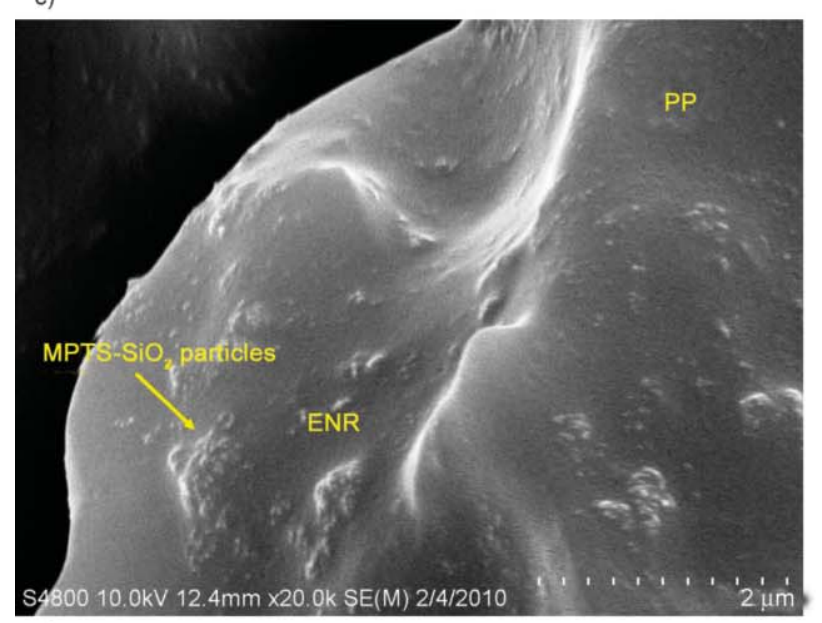

e)

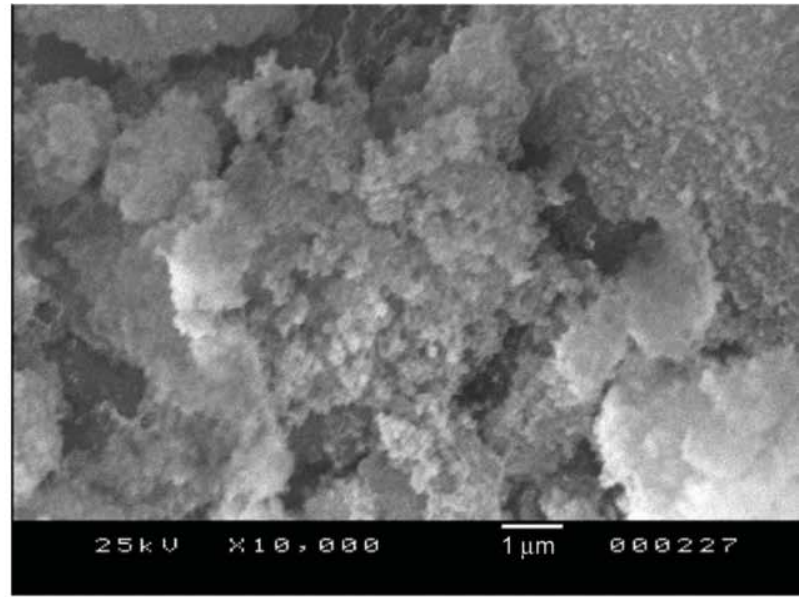

b)

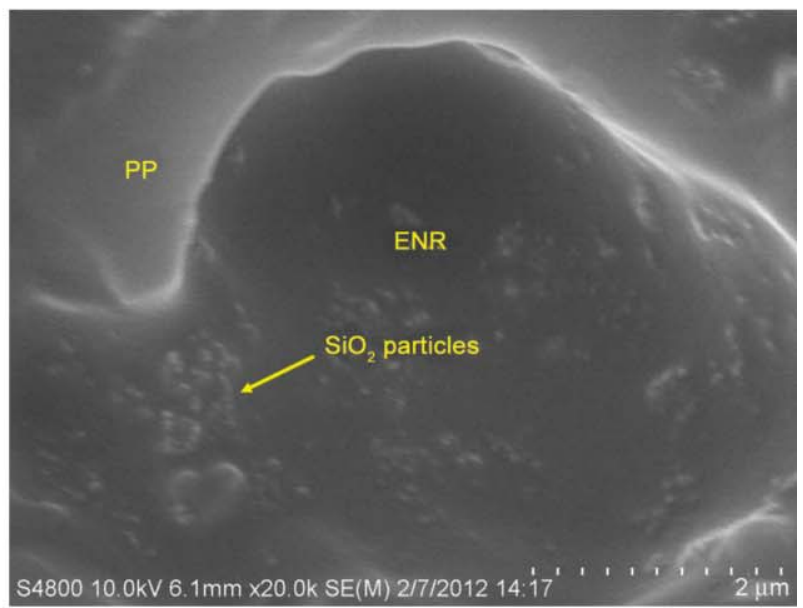

d)

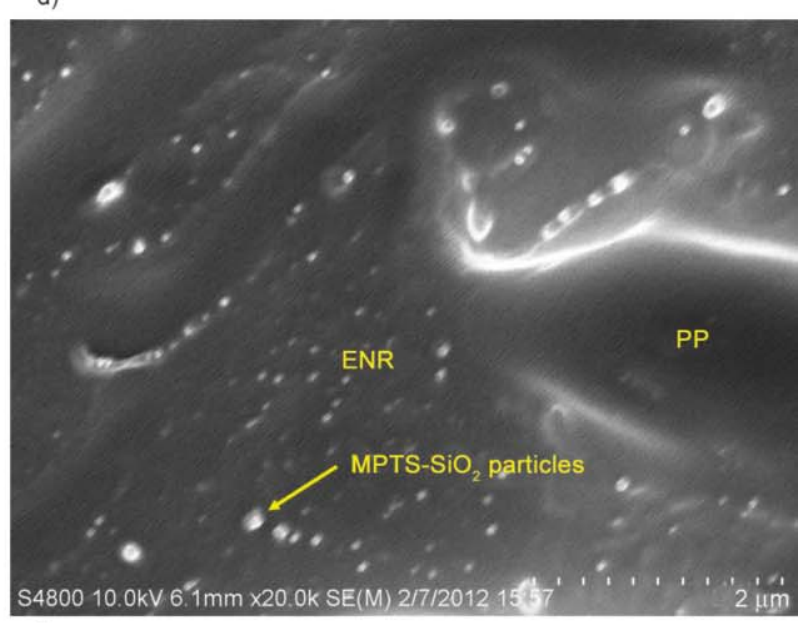

f)

Figure 2. SEM images of unmodified nano-silica (a), MPTS modified nano-silica (b) with a magnification of $10000 \times$ and unextracted TPNR nanocomposites with a magnification of $20000 \times$ : s-TPNR-SiO 2 (c); 1-TPNR-SiO 2 (d); s-TPNR-MPTS-SiO 2 (e); and 1TPNR-MPTS-SiO 2 (f).

pre-compounding samples. In fact, the incorporation of MPTS-SiO${ }_{2}$ via the latex pre-compounding showed the finest dispersion of silica nanoparticles in the TPNR. This could be attributed to the chemical modification of $\mathrm{SiO}_{2}$ with MPTS modifying the surface properties of $\mathrm{SiO}_{2}$ from a hydrophilic to a hydrophobic nature, resulting in the surface of the silica particles being covered by hydrophobic functional groups. This results in lower filler-filler interactions among the neighboring filler particles. This also leads to an enhancement in the compatibility between $\mathrm{SiO}_{2}$ and the ENR and, therefore, also the PP in the ENR/PP blends. The hydrophobicity of MPTS-SiO particles was verified by floating in water. It was 


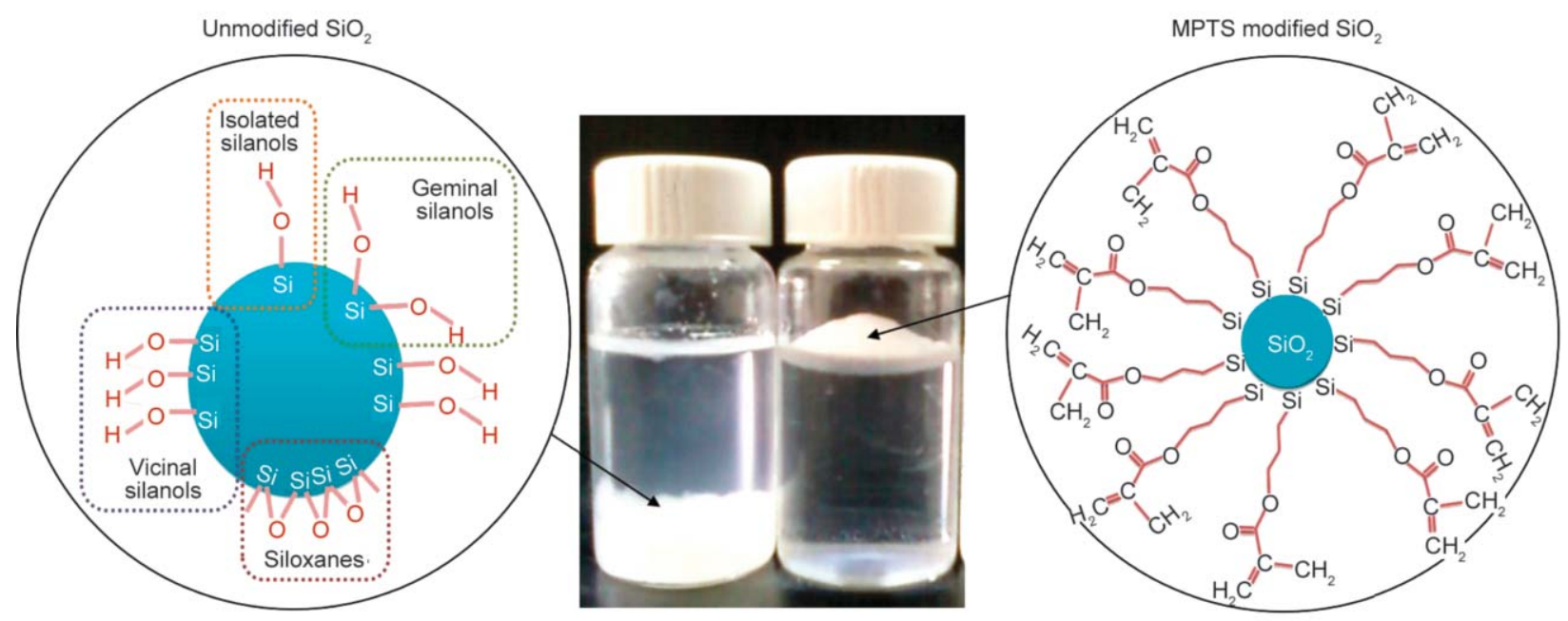

Figure 3. Images and model representation of hydrophilic groups at the $\mathrm{SiO}_{2}$ surface (sink in water) and hydrophobic groups at MPTS modified $\mathrm{SiO}_{2}$ surface (i.e., MPTS-SiO 2 ) (float in water).

found that the MPTS modified $\mathrm{SiO}_{2}$ particles floated on the water surface while the unmodified $\mathrm{SiO}_{2}$ particles sunk to the bottom of the container, as shown in Figure 3. The functional groups at the surface of unmodified $\mathrm{SiO}_{2}$ and MPTS modified particles are also shown in this figure.

\subsection{Mechanical properties}

Figure 4 shows typical stress-strain behaviors of TPNR and its nanocomposites with two different incorporating techniques of $\mathrm{SiO}_{2}$ (i.e., solid and latex pre-compounding techniques) and two different types of nano-silica (i.e., unmodified and MPTS modified $\mathrm{SiO}_{2}$ ). Also, the tensile properties in terms of Young's modulus, tensile strength, and elongation at break are summarized in Table 2. It can be seen that all types of TPNRs exhibited a combination of plastic and elastic behaviors during deformation according to the specific behaviors of thermoplastic elastomers. Furthermore, the addition of nano-silica into ENR and the ENR/PP blends led to lower strain but higher strength at break as compared with the blend without silica. This might be due to the materials having more rigidity in the presence of nano-silica.

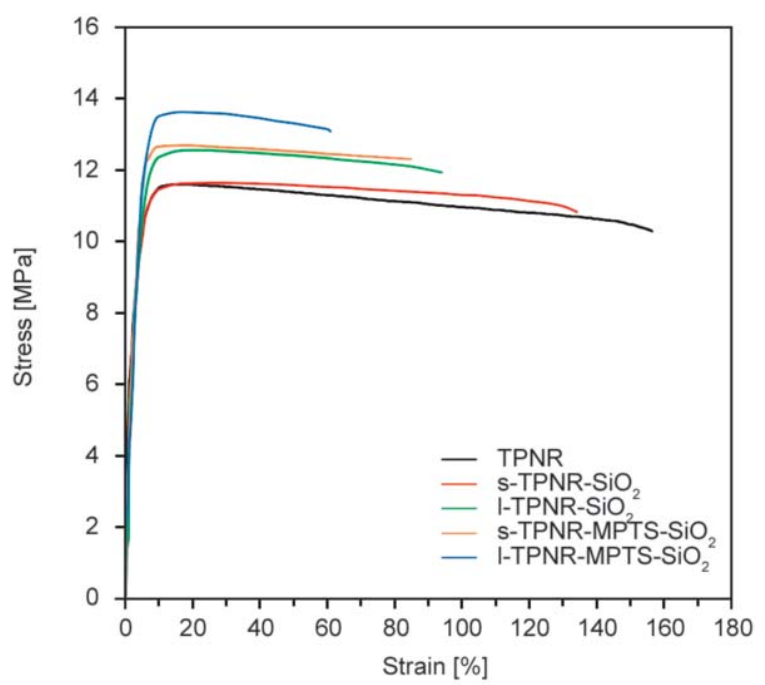

Figure 4. Stress-strain curves of TPNR and its nanocomposites with pre-compounding technique and surface modification of nano-silica.

In Figure 4, it can also be seen that the TPNR nanocomposites prepared by the latex pre-compounding technique had higher tensile strength and lower elongation at break as compared with those prepared using the solid pre-compounding technique. This can be attributed to better dispersion of nano-silica in the

Table 2. Tensile properties of TPNR and its nanocomposites with different pre-compounding technique and surface modification of nano-silica.

\begin{tabular}{|l|c|c|c|}
\hline \multicolumn{1}{|c|}{ Samples } & $\begin{array}{c}\text { Young's modulus } \\
\text { [MPa] }\end{array}$ & $\begin{array}{c}\text { Tensile strength } \\
{[\mathbf{M P a}]}\end{array}$ & $\begin{array}{c}\text { Elongation at break } \\
{[\%]}\end{array}$ \\
\hline TPNR & $299 \pm 10$ & $10.47 \pm 0.35$ & $156 \pm 15$ \\
\hline $\mathrm{s}-\mathrm{TPNR}-\mathrm{SiO}_{2}$ & $292 \pm 12$ & $10.83 \pm 0.60$ & $134 \pm 25$ \\
\hline s-TPNR-MPTS-SiO & & $11.42 \pm 0.45$ & $115 \pm 10$ \\
\hline 1-TPNR- $\mathrm{SiO}_{2}$ & $227 \pm 9$ & $11.94 \pm 0.20$ & $94 \pm 13$ \\
\hline 1-TPNR-MPTS-SiO & $289 \pm 5$ & $13.09 \pm 0.18$ & $61 \pm 15$ \\
\hline
\end{tabular}




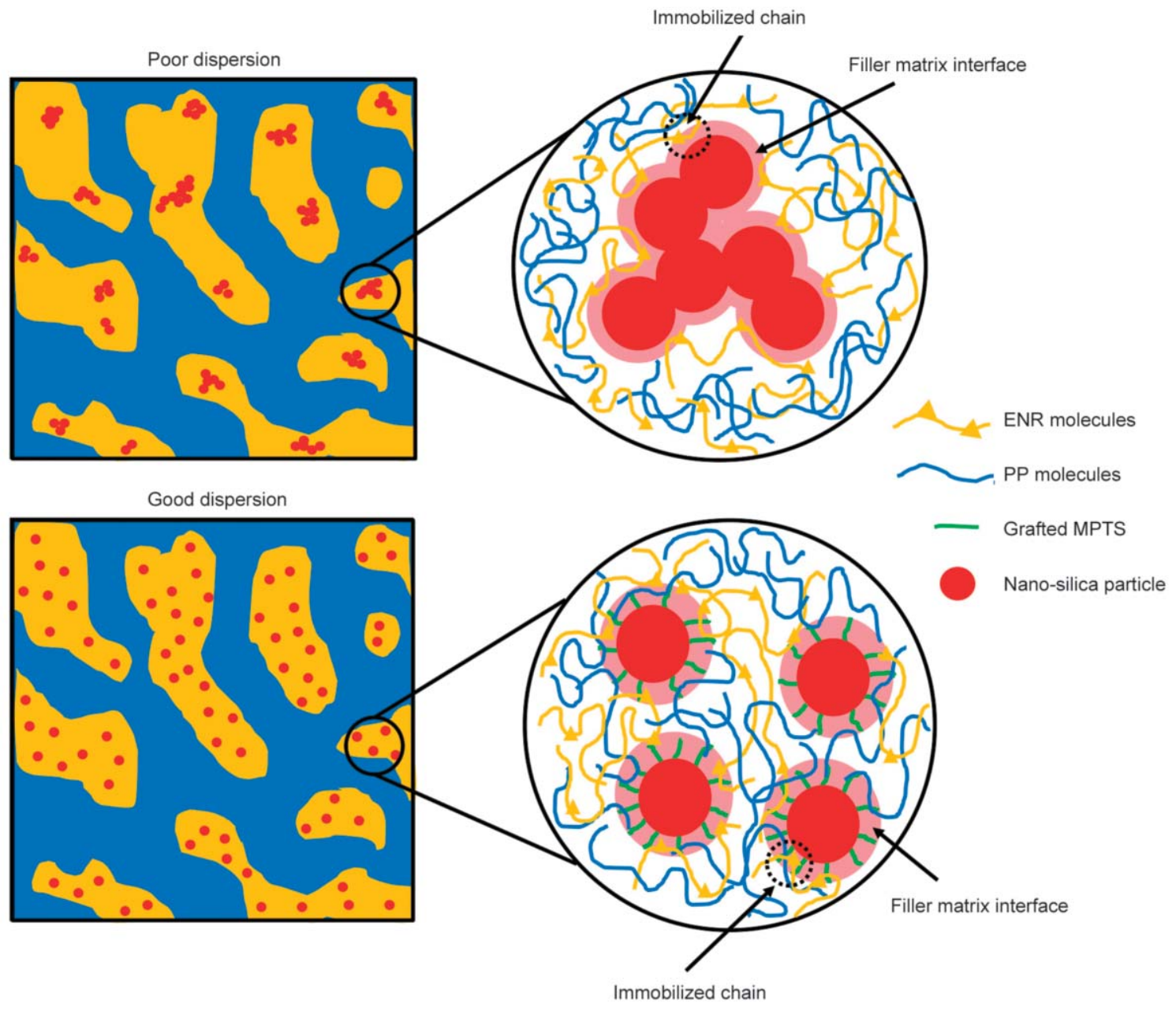

Figure 5. Schematic representation of compatibilization effect in TPNR filled with unmodified $\mathrm{SiO}_{2}$ and MPTS modified $\mathrm{SiO}_{2}$.

ENR and hence in the TPNR, causing the enhancement of the stress transfer between filler and the matrix leading to superior strength properties. In Figure 4 and Table 2, a dramatic improvement in tensile strength is clearly seen upon the addition of MPTS$\mathrm{SiO}_{2}$ into the ENR/PP blend, particularly with the ENR masterbatch blend prepared using the latex precompounding technique (1-TPNR-MPTS-SiO ${ }_{2}$ ). This might be attributed to higher compatibilization between the polymer phase in TPNR and $\mathrm{SiO}_{2}$ nanoparticles via grafted MPTS molecules. This might cause the formation of the immobilized chains of ENR and PP on the surface of MPTS-SiO 2 , as shown in the proposed model in Figure 5.

In order to understand more deeply the morphological properties of TPNR filled with nano-silica, SEM was performed, and the results are shown in Figure 6. It should be noted that the ENR phase in ENR/PP TPNR was extracted by etching with chloroform. Typically, the improvement of compatibility between different phases causes the reduction of interfacial tension, which has a great influence on the decreased droplet sizes of the blend morphology [1, 5, 31]. In Figure 6, it is clear that dual-phase co-continuous morphology is seen in all samples, indicating phase separation of the blends due to immiscibility between ENR and PP phases. It is also seen that the TPNR-SiO ${ }_{2}$ nanocomposites had smaller ENR domains where there were holes or cavities (Figures $6 \mathrm{~b}-$ 6e), as compared with the TPNR without filler (Figure 6a). This could imply that the $\mathrm{SiO}_{2}$ particles could prevent the coalescence of the ENR phase during processing and bring about an improvement in the compatibility between ENR and PP phases. Moreover, the TPNR filled with MPTS-SiO 2 (Figures $6 \mathrm{c}$ and $6 \mathrm{e}$ ) showed finer grain morphology than those of the unmodified $\mathrm{SiO}_{2}$ filled TPNR (Figures $6 \mathrm{~b}$ and $6 \mathrm{~d})$. This is attributed to higher interfacial adhesion and compatibility between different phases of the blends (i.e., ENR and PP) together with the MPTS$\mathrm{SiO}_{2}$ filler particles. Also, partial entanglement between PP/MPTS-SiO ${ }_{2}$ and ENR/MPTS-SiO ${ }_{2}$ could 
form immobilized chains at the filler-polymer interface. Therefore, the grafted organosilane on the MPTS-SiO ${ }_{2}$ surfaces could act as an effective compatibilizing agent of the ENR/PP blends, as shown in the schematic diagram in Figure 5. Hence, the greatest improvement of the phase morphology is to be found in the TPNR with MPTS-SiO 2 .
In Table 2, it can be seen that the addition of nanosilica in TPNR caused a slight reduction of Young's modulus in the TPNRs. This reduction was more pronounced in the TPNR with MPTS-SiO 2 . This might be due to grafted MPTS molecules on the $\mathrm{SiO}_{2}$ surface causing softening of the silica particles, leading to a decrease in the modulus of nano-silica

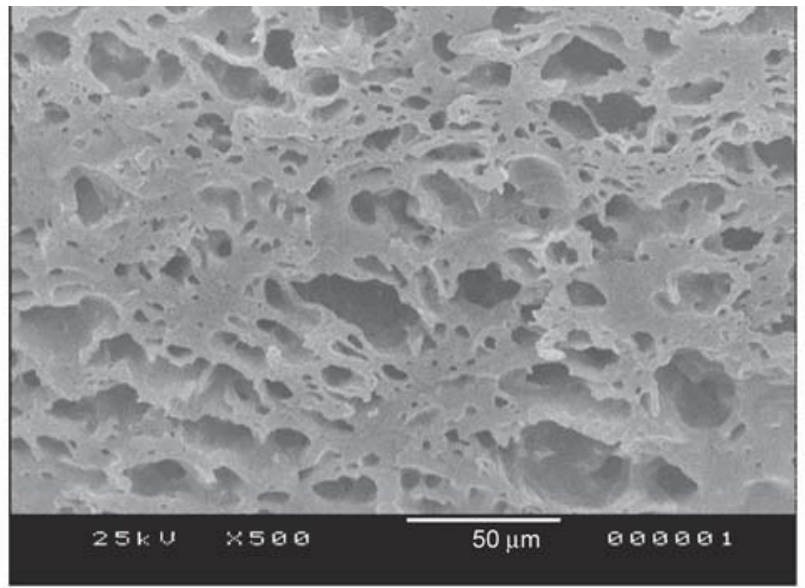

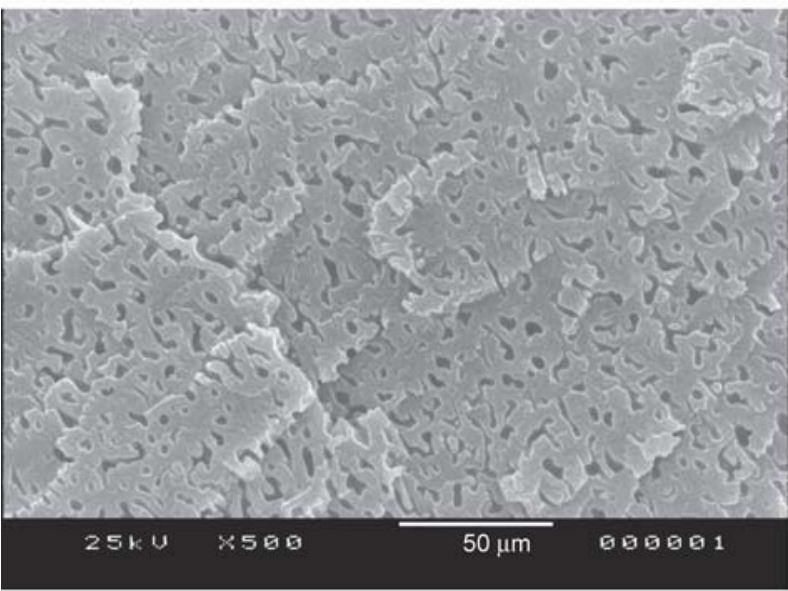

b)

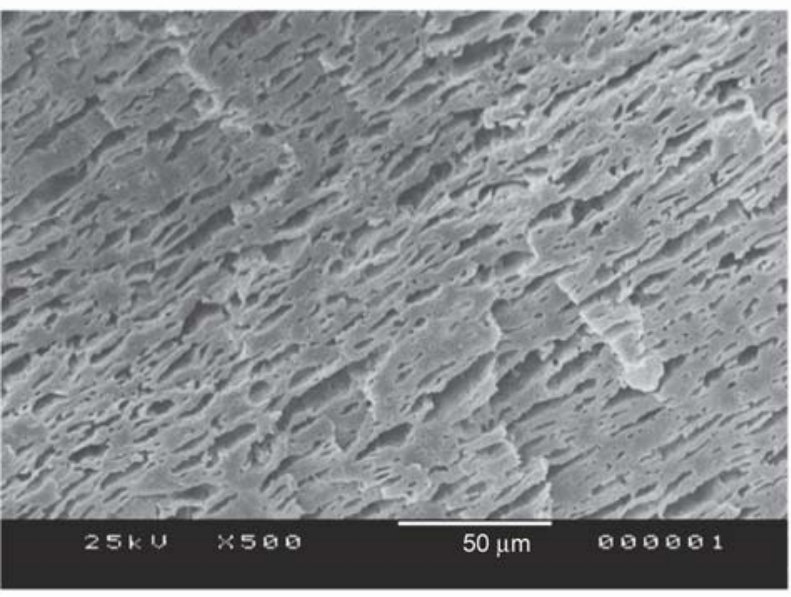

d)

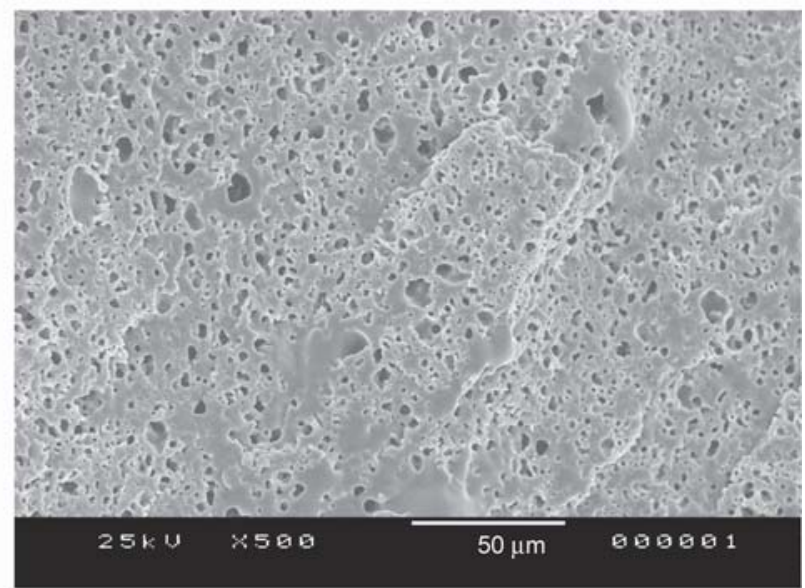

c)

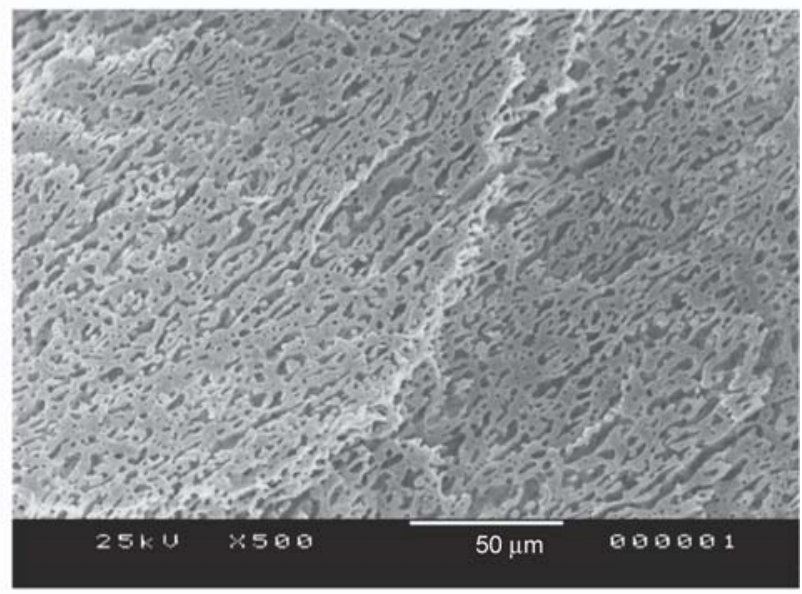

e)

Figure 6. SEM images of TPNR and its nanocomposites with a magnification of 500×: TPNR (a); s-TPNR-SiO 2 (b); s-TPNRMPTS-SiO 2 (c); 1-TPNR-SiO 2 (d); and 1-TPNR-MPTS-SiO 2 (e). 
particles and hence also of the TPNR. The reduction of Young's modulus upon adding modified $\mathrm{SiO}_{2}$ into the polymer matrix has been found in stiffened materials, such as HDPE [36] and PP [37]. However, it was found that the difference in the pre-compounding techniques did not affect the magnitude of Young's modulus of the TPNR nanocomposites.

\subsection{Thermal properties}

The thermal stability of TPNR and its nanocomposites with $2.5 \mathrm{wt} \%$ of nano-silica (i.e., $\mathrm{SiO}_{2}$ or MPTS$\mathrm{SiO}_{2}$ ) was determined by thermogravimetric analysis (TGA) in a nitrogen atmosphere, as shown in Figure 7. A summary of the TGA data is shown in Table 3. All the samples showed two decomposition steps, including decomposition of ENR phase at around $395-403^{\circ} \mathrm{C}$ and decomposition of PP phase at around $462-475^{\circ} \mathrm{C}$. In this work, it is clear that the addition of $\mathrm{SiO}_{2}$ particles into ENR/PP blends significantly increased initial decomposition temperature (IDT) as well as the decomposition temperature

Table 3. Thermal properties of TPNR and its nanocomposites with different pre-compounding technique and surface modification of nano-silica.

\begin{tabular}{|c|c|c|c|}
\hline \multirow[t]{2}{*}{ Samples } & \multirow{2}{*}{$\begin{array}{l}\text { IDT } \\
{\left[{ }^{\circ} \mathbf{C}\right]}\end{array}$} & \multicolumn{2}{|c|}{$\begin{array}{c}\boldsymbol{T}_{\mathbf{d}} \\
{\left[{ }^{\circ} \mathbf{C}\right]}\end{array}$} \\
\hline & & ENR & PP \\
\hline TPNR & 368.70 & 395.03 & 462.47 \\
\hline s-TPNR-SiO ${ }_{2}$ & 372.54 & 400.83 & 472.29 \\
\hline s-TPNR-MPTS-SiO & 373.63 & 401.95 & 473.73 \\
\hline 1-TPNR-SiO 2 & 377.18 & 401.05 & 470.86 \\
\hline 1-TPNR-MPTS-SiO ${ }_{2}$ & 375.39 & 402.42 & 474.49 \\
\hline
\end{tabular}

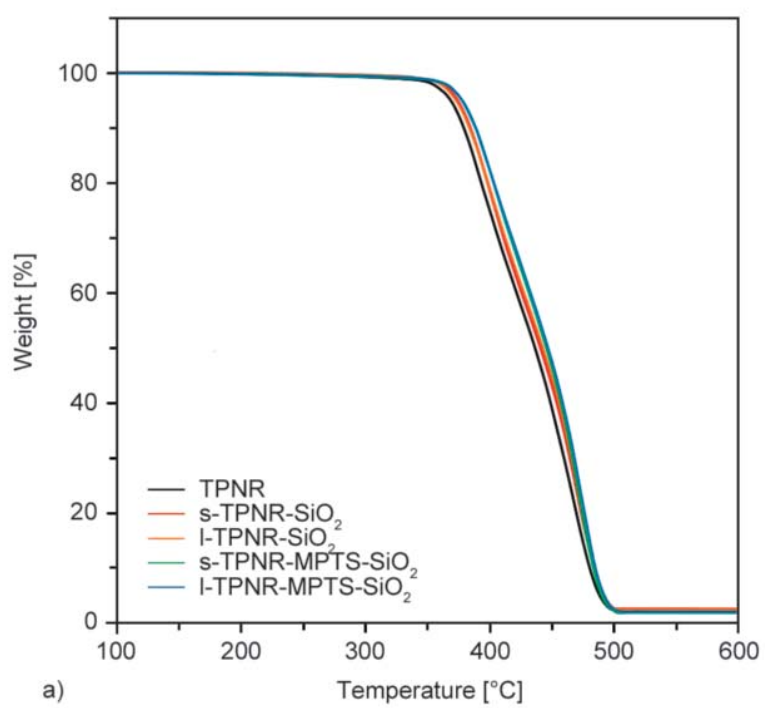

$\left(T_{\mathrm{d}}\right)$ of both ENR and PP phase indicating improvement in thermal stability of the TPNR nanocomposites. It is also seen that the $T_{\mathrm{d}}$ of TPNR nanocomposites filled with MPTS-SiO 2 are slightly higher than that of unmodified $\mathrm{SiO}_{2}$. Moreover, the latex pre-compounding of MPTS-SiO 2 in TPNR gave slightly higher $T_{\mathrm{d}}$ than that prepared by the solid precompounding technique. The increased thermal stability of TPNR can be explained by the enhancement of compatibilization between ENR and PP phases via the formation of immobilized chain (i.e., PP/ MPTS$\mathrm{SiO}_{2}$ and $\mathrm{ENR} / \mathrm{MPTS}-\mathrm{SiO}_{2}$ ) as discussed earlier.

\subsection{Crystallization behavior of the TPNR nanocomposites}

Besides the filler-polymer interaction that affects the mechanical and thermal properties of the TPNR nanocomposites, the strength properties are also governed by the molecular orientation of semi-crystalline PP phase through the crystallization process. Figure 8 shows cooling and heating DSC thermograms of TPNR and its nanocomposites with different precompounding techniques and surface modification of nano-silica. Also, Table 4 summarizes the crystallization temperature $\left(T_{\mathrm{pc}}\right)$, crystalline melting temperature $\left(T_{\mathrm{pm}}\right)$, and degree of crystallization $\left(X_{\mathrm{c}}\right)$ of PP phase in ENR/PP TPNR and its nanocomposites. In Figure 8a, it is clear that the cooling DSC thermograms indicate the crystallization temperature $\left(T_{\mathrm{pc}}\right)$ of the PP phase in pure ENR/PP TPNR at $107^{\circ} \mathrm{C}$ (Table 4). It can also be seen that the $T_{\mathrm{pc}}$ of PP phase in ENR/PP TPNR with unmodified $\mathrm{SiO}_{2}$ shows a

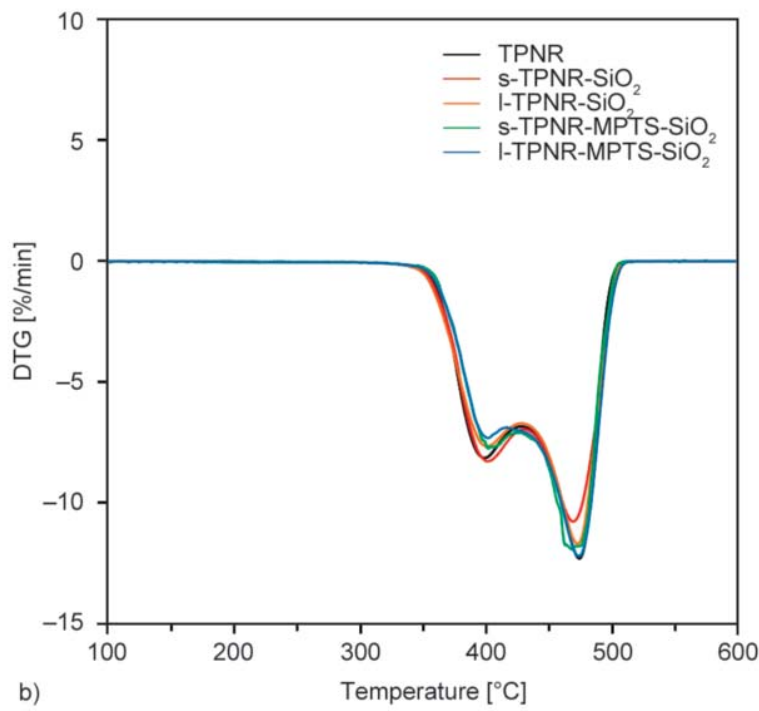

Figure 7. TGA (a) and DTG (b) curves of TPNR and its nanocomposites with different pre-compounding technique and surface modification of nano-silica. 

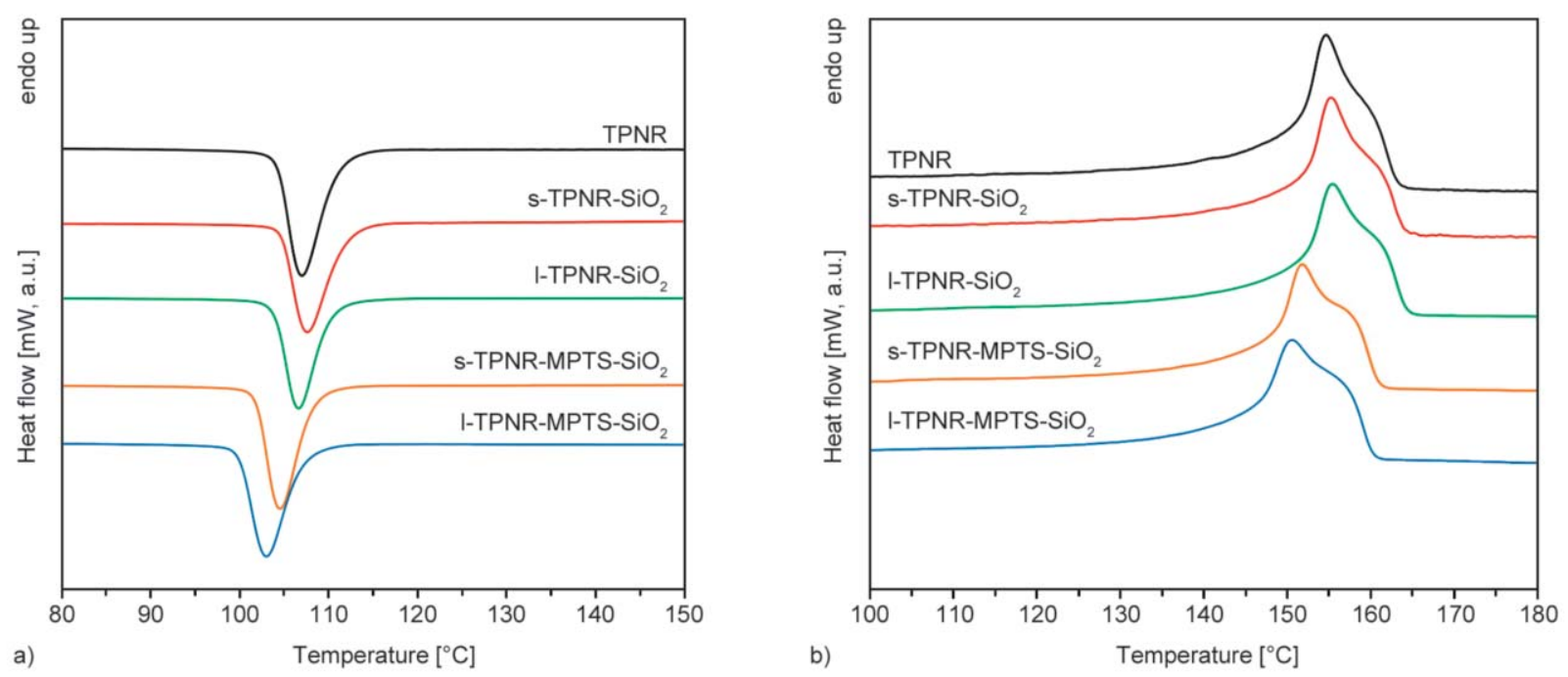

Figure 8. Cooling (a) and heating DSC thermogram (b) of TPNR and its nanocomposites with different pre-compounding technique and surface modification of nano-silica.

Table 4. Crystallization temperature $\left(T_{\mathrm{pc}}\right)$, crystalline melting temperature $\left(T_{\mathrm{pm}}\right)$ and degree of crystallization $\left(X_{\mathrm{c}}\right)$ of PP phase in ENR/PP TPNR and its nanocomposites with different pre-compounding techniques and surface modification of nano-silica.

\begin{tabular}{|c|c|c|c|c|}
\hline Samples & $\begin{array}{c}T_{\mathbf{p c}} \\
{\left[{ }^{\circ} \mathbf{C}\right]}\end{array}$ & $\begin{array}{c}T_{\mathrm{pm}} \\
{\left[{ }^{\circ} \mathbf{C}\right]}\end{array}$ & $\begin{array}{l}\Delta \boldsymbol{H}_{\mathrm{m}} \\
{[\mathbf{J} / \mathrm{g}]}\end{array}$ & $\begin{array}{c}X_{\mathbf{c}} \\
{[\%]}\end{array}$ \\
\hline TPNR & 107.0 & 154.7 & 44.4 & 42.8 \\
\hline s-TPNR-SiO ${ }_{2}$ & 107.6 & 155.2 & 42.1 & 42.7 \\
\hline s-TPNR-MPTS-SiO & 104.5 & 151.7 & 43.6 & 44.2 \\
\hline 1-TPNR-SiO 2 & 106.0 & 154.5 & 42.2 & 42.5 \\
\hline 1-TPNR-MPTS-SiO & 103.0 & 150.5 & 43.8 & 44.4 \\
\hline
\end{tabular}

similar value to the TPNR without silica (i.e., pure TPNR), in concurrence with earlier studies $[3,17]$. However, the crystallization peaks (i.e., $T_{\mathrm{pc}}$ ) of the PP phase in the TPNR nanocomposites with MPTS$\mathrm{SiO}_{2}$ were significantly shifted to lower temperatures (i.e., $104.5^{\circ} \mathrm{C}$ in s-TPNR-MPTS- $\mathrm{SiO}_{2}$ and $103^{\circ} \mathrm{C}$ in 1-TPNR-MPTS-SiO${ }_{2}$ ). This implies the interference of nucleation of the PP phase in the ENR/PP blend in the commencement of the crystallization because of the MPTS-SiO${ }_{2}$ nanoparticles. That is, the grafted MPTS on nano-silica surfaces might cause partial absorption of PP chains on the silica surfaces by chemical and physical interaction as well as chain entanglement and hence retard the crystallization process. This might disturb the rearrangement of the chain-folding mechanisms of PP segments to crystallize. This is why the retardation of the nucleation process of the PP phase in the MPTS-SiO ${ }_{2}$ filled ENR/PP TPNR nanocomposite occurred, as indicated by the lowest $T_{\mathrm{pc}}$ (Table 4). This phenomenon has also been found in the HDPE phase in the NR/HDPE blend compatibilized with graphene oxide (GO) [31] and maleic anhydride grafted polypropylene ( $\mathrm{mPP}) /$ layered silicate (OLS) hybrids [38].

Figure $8 \mathrm{~b}$ shows the heating DSC thermograms of pure TPNR and its nanocomposites. The double crystalline melting peaks are seen clearly in all samples, which indicates the presence of monoclinic $\alpha$ form and hexagonal $\beta$-form of PP crystallites [39], respectively. It is also seen that the crystalline melting temperature $\left(T_{\mathrm{pm}}\right)$ of the PP phase in the ENR/PP blend filled with unmodified $\mathrm{SiO}_{2}$ prepared by solid and latex pre-compounding techniques are similar to that of the $T_{\mathrm{pm}}$ of pure TPNR. However, the addition of $\mathrm{MPTS}-\mathrm{SiO}_{2}$ into the ENR/PP blend caused markedly decreased $T_{\mathrm{pm}}$, corresponding to the reduction in the size of spherulite in the crystalline PP phase, explaining the imperfect crystals of PP [40]. It is worth noting that the degree of crystallinity $\left(X_{\mathrm{c}}\right)$ of the PP phase in the ENR/PP TPNR was slightly increased upon the addition of the MPTS-SiO 2 . However, similar $X_{\mathrm{c}}$ was observed in the pure TPNR, and unmodified $\mathrm{SiO}_{2}$ filled TPNR, both prepared by solid and latex pre-compounding techniques. The increase in the degree of crystallinity of the PP phase in the ENR/PP TPNR with MPTS-SiO ${ }_{2}$ could be explained by the higher dispersion capacity of the MPTS- $\mathrm{SiO}_{2}$ nanoparticles in the ENR and eventually some in PP phases, which caused an increase in the effective number of nuclei available to promote crystallization and hence increased the degree of crystallinity. 


\subsection{X-ray diffraction (XRD) analysis}

Figure 9 shows XRD patterns of the PP phase in ENR/PP TPNR and its nanocomposites with different pre-compounding techniques and the surface modification of nano-silica. The peaks at $2 \theta=14.0$, $16.8,18.5,21.3$, and $21.8^{\circ}$ correspond to the $\alpha$-form peaks of PP at (110), (040), (130), (111) and (041) planes were observed, respectively. Also, the $\beta$-form of PP at the (300) plane was observed in all samples at $2 \theta=16.0^{\circ}$. This result correlates well to the double melting peaks of DSC thermograms (Figure 8b). It is seen that all the TPNR samples did not show any new peak location; they remained nearly unchanged, as compared to the peaks of pure TPNR. This indicates that different pre-compounding techniques and surface modification of $\mathrm{SiO}_{2}$ did not affect the crystalline structure of the PP phase in the ENR/PP blend. This concurs with our previous study [3]; that is, the addition of $2.5 \mathrm{wt} \%$ nano-silica in 50/50 ENR/PP blends did not change the XRD diffraction pattern of PP crystalline. Therefore, the enhancement of mechanical and thermal properties of 50/50 ENR/PP TPNR filled with $2.5 \mathrm{wt} \%$ nano-silica should be attributed to the uniform dispersion of nano-silica particles, strong filler-polymer interactions, and the degree of crystallinity of the PP phase.

\section{Conclusions}

Various properties of the 50/50 ENR/PP TPNR with $2.5 \mathrm{wt} \%$ of unmodified and MPTS modified nanosilica particles ( $\mathrm{SiO}_{2}$ and MPTS-SiO 2 , respectively)

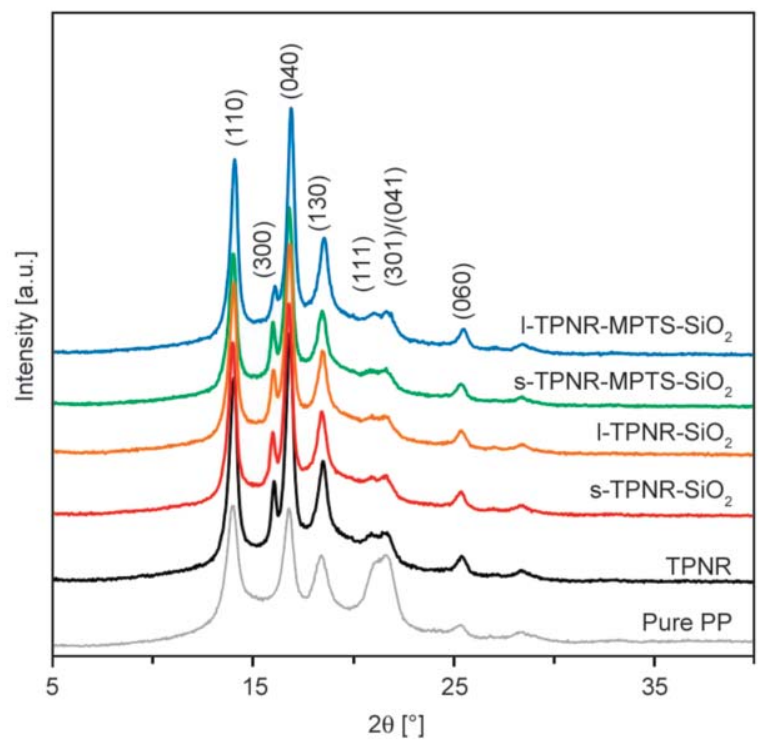

Figure 9. XRD patterns of TPNR and its nanocomposites with different pre-compounding technique and surface modification of nano-silica. prepared using latex and solid pre-compounding techniques were investigated. The effect of the processing method and surface modification of nano-silica on phase morphology, mechanical properties, thermal stability, and crystallinity of the PP phase in the ENR/PP blend was studied. It was found that the finer dispersion of nano-silica was found in the blends using the ENR-silica masterbatch prepared using the latex pre-compounding technique. This leads to an increase in mechanical properties and thermal stability of the ENR/PP TPNR nanocomposites. In addition, the highest degree of dispersion of nano-silica was achieved by the addition of ENR mixed with MPTS-SiO 2 . This resulted in superior mechanical properties for the TPNR nanocomposites filled with MPTS-SiO 2 . This can be ascribed to the increased interfacial interaction between the polymer matrix and nano-silica particles, causing a strong filler-polymer interaction and improvement of compatibilization between the different polymer phases (i.e., ENR and $\mathrm{PP}$ ) and filler particles (i.e., MPTS-SiO 2 ), leading to the ability of filler to support stresses transferred from the polymer matrix. The thermal stability of the TPNR nanocomposites was also significantly improved in the presence of MPTS-SiO 2 .

Furthermore, a higher degree of crystallinity in the PP phase in ENR/PP TPNR with MPTS-SiO 2 particles was observed, while the different pre-compounding techniques and introduction of $\mathrm{SiO}_{2}$ did not show any significant change in the degree of crystallinity in the PP phase. Moreover, the XRD results indicate that the crystalline structure of the PP phase in the 50/50 ENR/PP blends was not affected by the addition of $2.5 \mathrm{wt} \%$ nano-silica $\left(\mathrm{SiO}_{2}\right.$ or MPTS-SiO 2$)$. Therefore, we suggest that the ENR/PP TPNR nanocomposites with finer dispersion and distribution of nano-silica with superior mechanical and thermal properties could be obtained via the latex pre-compounding technique together with the use of surface modified nano-silica.

\section{Acknowledgements}

This project is supported by Central Public-Interest Scientific Institution Basal Research Fund for Chinese Academy of Tropical Agricultural Sciences (Grant number 1630122017003), Central Public-interest Scientific Institution Basal Research Fund for Chinese Academy of Tropical Agricultural Sciences (Grant number 1630122021005), the Foundation of Guangdong Provincial Key Laboratory of Natural Rubber Processing, P.R. China (2019B121203004) and Graduate School Prince of Songkla University, Thailand. 


\section{References}

[1] Kalkornsurapranee E., Koedthip D., Songtipya P., Prodpran T., Johns J., Nakaramontri Y., Songtipya L.: Influence of modified natural rubbers as compatibilizers on the properties of flexible food contact materials based on NR/PBAT blends. Materials and Design, 196, 109134/1-109134/7 (2020).

https://doi.org/10.1016/j.matdes.2020.109134

[2] Lehman N., Songtipya L., Johns J., Maliwankul K., Voravuthikunchai S. P., Nakaramontri Y., Sengloyluan K., Kalkornsurapranee E.: Shape memory thermoplastic natural rubber for novel splint applications. Express Polymer Letter, 15, 28-38 (2021).

https://doi.org/10.3144/expresspolymlett.2021.4

[3] Jarnthong M., Nakason C., Lopattananon N., Peng Z.: Influence of incorporation sequence of silica nanoparticles on morphology, crystallization behavior, mechanical properties, and thermal resistance of melt blended thermoplastic natural rubber. Polymer Composites, 33, 1911-1920 (2012).

https://doi.org/10.1002/pc.22331

[4] Nakason C., Jarnthong M., Kaesaman A., Kiatkamjornwong S.: Influences of blend proportions and curing systems on dynamic, mechanical, and morphological properties of dynamically cured epoxidized natural rubber/high-density polyethylene blends. Polymer Engineering and Science, 49, 281-292 (2009). https://doi.org/10.1002/pen.21256

[5] Nakason C., Jarnthong M., Kaesaman A., Kiatkamjornwong S.: Thermoplastic elastomers based on epoxidized natural rubber and high-density polyethylene blends: Effect of blend compatibilizers on the mechanical and morphological properties. Journal of Applied Polymer Science, 109, 2694-2702 (2008). https://doi.org/10.1002/app.28265

[6] Nakason C., Saiwari S., Kaesaman A.: Rheological properties of maleated natural rubber/polypropylene blends with phenolic modified polypropylene and polypropylene- $g$-maleic anhydride compatibilizers. Polymer Testing, 25, 413-423 (2006).

https://doi.org/10.1016/j.polymertesting.2005.11.006

[7] Pichaiyut S., Nakason C., Kaesaman A., Kiatkamjornwong S.: Influences of blend compatibilizers on dynamic, mechanical, and morphological properties of dynamically cured maleated natural rubber and high-density polyethylene blends. Polymer Testing, 27, 566-580 (2008). https://doi.org/10.1016/j.polymertesting.2008.03.004

[8] Kalkornsurapranee E., Vennemann N., Kummerlöwe C., Nakason C.: Novel thermoplastic natural rubber based on thermoplastic polyurethane blends: Influence of modified natural rubbers on properties of the blends. Iranian Polymer Journal, 21, 689-700 (2012).

https://doi.org/10.1007/s13726-012-0075-5

[9] Salaeh S., Banda T., Pongdong V., Wießner S., Das A., Thitithammawong A.: Compatibilization of poly(vinylidene fluoride)/natural rubber blend by poly(methyl methacrylate) modified natural rubber. European Polymer Journal, 107, 132-142 (2018).

https://doi.org/10.1016/j.eurpolymj.2018.08.007
[10] Azlina H. N., Sahrim H. A., Rozaidi R.: Enhanced tensile and dynamic mechanical properties of thermoplastic natural rubber nanocomposites. Polymer-Plastics Technology and Engineering, 50, 1383-1387 (2011). https://doi.org/10.1080/03602559.2011.578295

[11] Azlina H. N., Sahrim H. A., Rozaidi R.: Effect of nanoclay on the microstructure and the properties of thermoplastic natural rubber (TPNR)/OMMT nanocomposites. Journal of Thermoplastic Composite Materials, 25, 351-362 (2011).

https://doi.org/10.1177/0892705711408987

[12] Nair S. T., Vijayan P. P., George S. C., Kalarikkal N., Thomas S.: Enhanced mechanical and thermal performance of multiwalled carbon nanotubes-filled polypropylene/natural rubber thermoplastic elastomers. New Journal of Chemistry, 45, 4963-4976 (2021).

https://doi.org/10.1039/D0NJ05437B

[13] Tarawneh M. A., Ahmad S., Chen R. S.: Mechanical, thermal, and electrical properties of graphene oxidemultiwalled carbon nanotubes-filled thermoplastic elastomer nanocomposite. Journal of Elastomers and Plastics, 49, 345-355 (2016). https://doi.org/10.1177/0095244316661753

[14] Flaifel M. H., Zakaria M. Z., Ahmad S. H.: The influence of adopted chemical modification route on the thermal and mechanical properties of alumina nanoparticles-impregnated thermoplastic natural rubber nanocomposite. Arabian Journal for Science and Engineering, 45, 1181-1190 (2020). https://doi.org/10.1007/s13369-019-04279-7

[15] Yu L-J., Ahmad S. H., Kong I., Tarawneh M. A., Abd Razak S. B. B., Natarajan E., Ang C. K.: Magnetic, thermal stability and dynamic mechanical properties of beta isotactic polypropylene/natural rubber blends reinforced by NiZn ferrite nanoparticles. Defence Technology, 15, 958-963 (2019). https://doi.org/10.1016/j.dt.2019.03.001

[16] Flaifel M. H., Ahmad S. H., Abdullah M. H., Al-Asbahi B. A.: NiZn ferrite filled thermoplastic natural rubber nanocomposites: Effect of low temperature on their magnetic behaviour. Cryogenics, 52, 523-529 (2012). https://doi.org/10.1016/j.cryogenics.2012.06.009

[17] Aso O., Eguiazábal J. I., Nazábal J.: The influence of surface modification on the structure and properties of a nanosilica filled thermoplastic elastomer. Composites Science and Technology, 67, 2854-2863 (2007). https://doi.org/10.1016/j.compscitech.2007.01.021

[18] Castellano M., Conzatti L., Turturro A., Costa G., Busca G.: Influence of the silane modifiers on the surface thermodynamic characteristics and dispersion of the silica into elastomer compounds. Journal of Physical Chemistry B, 111, 4495-4502 (2007). https://doi.org/10.1021/jp0702144 
[19] Fukuyama Y., Senda M., Kawai T., Kuroda S-I., Toyonaga M., Taniike T., Terano M.: The effect of the addition of polypropylene-grafted $\mathrm{SiO}_{2}$ nanoparticle on the thermal conductivity of isotactic polypropylene. Journal of Thermal Analysis and Calorimetry, 117, 1397 1405 (2014).

https://doi.org/10.1007/s10973-014-3881-5

[20] Jarnthong M., Peng Z., Lopattananon N., Nakason C.: Nanosilica-reinforced epoxidized natural rubber nanocomposites: Effect of epoxidation level on morphological and mechanical properties. Polymer Composites, 38, 1151-1157 (2017). https://doi.org/10.1002/pc.23678

[21] Kaewsakul W., Sahakaro K., Dierkes W. K., Noordermeer J. W. M.: Cooperative effects of epoxide functional groups on natural rubber and silane coupling agents on reinforcing efficiency of silica. Rubber Chemistry and Technology, 87, 291-310 (2014). https://doi.org/10.5254/RCT.13.86990

[22] Zheng J., Han D., Ye X., Wu X., Wu Y., Wang Y., Zhang L.: Chemical and physical interaction between silane coupling agent with long arms and silica and its effect on silica/natural rubber composites. Polymer, 135, 200 210 (2018).

https://doi.org/10.1016/j.polymer.2017.12.010

[23] George N., Venugopal B., John H., Mathiazhagan A., Joseph R.: Nanosilica decorated multiwalled carbon nanotubes (CS hybrids) in natural rubber latex. Polymer, 161, 170-180 (2019).

https://doi.org/10.1016/j.polymer.2018.12.014

[24] George N., Bipinbal P. K., Bhadran B., Mathiazhagan A., Joseph R.: Segregated network formation of multiwalled carbon nanotubes in natural rubber through surfactant assisted latex compounding: A novel technique for multifunctional properties. Polymer, 112, 264-277 (2017). https://doi.org/10.1016/j.polymer.2017.01.082

[25] Hayeemasae N., Rathnayake W. G. I. U., Ismail H.: Nano-sized $\mathrm{TiO}_{2}$-reinforced natural rubber composites prepared by latex compounding method. Journal of Vinyl and Additive Technology, 23, 200-209 (2017).

https://doi.org/10.1002/vnl.21497

[26] Peng Z., Feng C., Luo Y., Li Y., Kong L.: Self-assembled natural rubber/multi-walled carbon nanotube composites using latex compounding techniques. Carbon, 48, 4497-4503 (2010). https://doi.org/10.1016/j.carbon.2010.08.025

[27] Xia L., Song J., Wang H., Kan Z.: Silica nanoparticles reinforced natural rubber latex composites: The effects of silica dimension and polydispersity on performance. Journal of Applied Polymer Science, 136, 47449/147449/11 (2019).

https://doi.org/10.1002/app.47449

[28] Fathurrohman M. I., Rugmai S., Hayeemasae N., Sahakaro K.: Dispersion and properties of natural rubber-montmorillonite nanocomposites fabricated by novel in situ organomodified and latex compounding method. Polymer Engineering and Science, 59, 1830-1839 (2019). https://doi.org/10.1002/pen.25183
[29] Siririttikrai N., Thanawan S., Suchiva K., Amornsakchai T.: Comparative study of natural rubber/clay nanocomposites prepared from fresh or concentrated latex. Polymer Testing, 63, 244-250 (2017). https://doi.org/10.1016/j.polymertesting.2017.08.015

[30] Sun Y., Cheng Z., Zhang L., Jiang H., Li C.: Promoting the dispersibility of silica and interfacial strength of rubber/silica composites prepared by latex compounding. Journal of Applied Polymer Science, 137, 49526/149526/14 (2020).

https://doi.org/10.1002/app.49526

[31] Yan N., Xia H., Wu J., Zhan Y., Fei G., Chen C.: Compatibilization of natural rubber/high density polyethylene thermoplastic vulcanizate with graphene oxide through ultrasonically assisted latex mixing. Journal of Applied Polymer Science, 127, 933-941 (2013). https://doi.org/10.1002/app.37861

[32 Jain S., Goossens H., van Duin M., Lemstra P.: Effect of in situ prepared silica nano-particles on non-isothermal crystallization of polypropylene. Polymer, 46, 88058818 (2005).

https://doi.org/10.1016/j.polymer.2004.12.062

[33] Walter R., Friedrich K., Privalko V., Savadori A.: On modulus and fracture toughness of rigid particulate filled high density polyethylene. Journal of Adhesion, 64, 87109 (1997). https://doi.org/10.1080/00218469708010533

[34] Rong M. Z., Zhang M. Q., Zheng Y. X., Zeng H. M., Walter R., Friedrich K.: Structure-property relationships of irradiation grafted nano-inorganic particle filled polypropylene composites. Polymer, 42, 167-183 (2001). https://doi.org/10.1016/S0032-3861(00)00325-6

[32] Derouet D., Mulder-Houdayer S., Brosse J. C.: Comparative study of the epoxidation of natural and synthetic rubber latices. Journal of Rubber Research, 9, 1-20 (2006).

[33] Heping Y., Sidong L., Zheng P.: Preparation and study of epoxidized natural rubber. Journal of Thermal Analysis and Calorimetry, 58, 293-299 (1999).

https://doi.org/10.1023/a:1010199013587

[37] Wunderlich B.: Thermal analysis. Academic Press, New York (1990).

[38] Kim B., Lee S-H., Lee D., Ha B., Park J., Char K.: Crystallization kinetics of maleated polypropylene/clay hybrids. Industrial and Engineering Chemistry Research, 43, 6082-6089 (2004). https://doi.org/10.1021/ie049825y

[39] Romankiewicz A., Sterzynski T., Brostow W.: Structural characterization of $\alpha$ - and $\beta$-nucleated isotactic polypropylene. Polymer International, 53, 2086-2091 (2004). https://doi.org/10.1002/pi.1632

[40] Jimenez G., Ogata N., Kawai H., Ogihara T.: Structure and thermal/mechanical properties of poly( $\varepsilon$-caprolactone)-clay blend. Journal of Applied Polymer Science, 64, 2211-2220 (1997). https://doi.org/10.1002/(SICI)10974628(19970613)64:11<2211::AID-APP17>3.0.CO;2-6 